\title{
Efeito da desnutrição neonatal sobre o recrutamento celular e a atividade oxidante-antioxidante de macrófagos em ratos adultos endotoxêmicos ${ }^{1}$
}

\section{Effect of neonatal malnutrition on cell recruitment and oxidant-antioxidant activity of macrophages} in endotoxemic adult rats

\author{
Juliana Félix de MELO² \\ Érika Michelle Correia de MACEDO \\ Rebecca Peixoto Paes SILVA 2 \\ Marcelo Tavares VIANA ${ }^{3}$ \\ Wylla Tatiana Ferreira e SILVA ${ }^{3}$ \\ Célia Maria Machado Barbosa de CASTRO²
}

\section{RE S U M O}

\section{Objetivo}

Avaliar se a desnutrição no período neonatal produz prejuízos no recrutamento celular para o pulmão e na atividade oxidante-antioxidante de macrófagos alveolares em ratos adultos endotoxêmicos.

\section{Métodos}

Ratos machos Wistar $(\mathrm{n}=48$ ) foram alimentados por mães cuja dieta, durante a lactação, continha $23 \%$ de proteína no grupo nutrido e $8 \%$ no grupo desnutrido. Após o desmame todos os animais foram recuperados com dieta normoprotéica. Entre 90 e 120 dias, a metade de cada grupo foi submetida à endotoxemia por meio da administração por via intraperitonial (v.i) de lipopolissacarídio na dose de $1 \mathrm{mg} / \mathrm{kg}$ de peso corporal. Após 24 horas desse procedimento coletou-se o sangue para contagem total e diferencial de leucócitos e para a dosagem de óxido nítrico. Além do sangue coletou-se também o lavado broncoalveolar para contagem total

\footnotetext{
1 Artigo elaborado a partir da dissertação de J.F. MELO, intitulada "Atividade oxidante-antioxidante de macrófagos alveolares em ratos endotoxêmicos submetidos à desnutrição neonatal”. Universidade Federal de Pernambuco; 2007. Apoio: Conselho Nacional de Desenvolvimento Científico e Tecnológico (Processo n.4770004/04-0).

2 Universidade Federal de Pernambuco, Laboratório de Imunopatologia Keizo Asami, Setor de Microbiologia. Av. Prof. Moraes Rêgo, s/n., Cidade Universitária, 50670-420, Recife, PE, Brasil. Correspondência para/Correspondence to: C.M.M.B. de CASTRO. E-mail: <ccastro@lika.ufpe.br>.

3 Universidade Federal de Pernambuco, Departamento de Nutrição, Laboratório de Fisiologia. Recife, PE, Brasil.
} 
e diferencial de leucócitos e, a partir de macrófagos isolados deste lavado, foram realizadas as dosagens de superóxido, óxido nítrico e superóxido dismutase.

\section{Resultados}

A desnutrição acarretou um déficit ponderal que persistiu até a idade adulta, além disso, reduziu a contagem total de leucócitos sangüíneos e o número de neutrófilos após o estímulo com lipopolissacarídio. A atividade oxidante-antioxidante foi alterada havendo diminuição da produção de superóxido, óxido nítrico e superóxido dismutase antes e após a indução da endotoxemia.

\section{Conclusão}

Esses resultados sugerem que a desnutrição neonatal, mesmo após a recuperação nutricional, compromete o recrutamento celular para o pulmão e a atividade oxidante-antioxidante dos macrófagos alveolares em ratos adultos. A endotoxemia contribui para evidenciar essas seqüelas da resposta do hospedeiro frente a este modelo de desnutrição.

Termos de indexação: Desnutrição. Endotoxemia. Migração e rolagem de leucócitos. Superóxidos. Espécies reativas de nitrogênio. Superóxido dismutase.

\section{A B S T R A C T}

\section{Objective}

The objective of this study was to assess if neonatal malnutrition impairs cell recruitment to the lungs and the oxidant-antioxidant activity of alveolar macrophages in adult endotoxemic rats.

\section{Methods}

Male Wistar rats $(n=48)$ were divided into two groups and suckled by dams fed experimental diets containing a normal protein content of 23\% (nourished group) and a low protein content of $8 \%$ (undernourished group) during lactation. After weaning, all animals received a normal protein diet. Between 90 and 120 days, half of each group was submitted to endotoxemia by intraperitoneal administration of $1 \mathrm{mg} / \mathrm{kg}$ of body weight of lipopolysaccharide. Blood was collected 24 hours after this procedure for total and differential leukocyte count and measurement of nitric oxide. Bronchoalveolar lavage was also done to determine total and differential leukocyte count and measure superoxide, nitric oxide and superoxide dismutase in the macrophages isolated from this lavage.

\section{Results}

Malnourished animals remained underweight until adulthood. Furthermore, the following also decreased: total blood leukocyte count, number of neutrophils after lipopolysaccharide administration and production of superoxide, nitric oxide and superoxide dismutase before and after induced endotoxemia.

\section{Conclusion}

These results suggest that neonatal malnutrition, even after nutritional recovery, compromises cell recruitment to lungs and the oxidant-antioxidant activity of alveolar macrophages of adult rats. Endotoxemia contributes to evidence these sequelae to the host response before this model of malnutrition.

Indexing terms: Malnutrition. Endotoxemia. Leukocyte rolling. Superoxides. Reactive nitrogen species. Superoxide dismutase.

\section{N T R O D U Ç Ã O}

Ao atuar no período crítico de desenvolvimento dos sistemas orgânicos, a deficiência nutricional é capaz de interferir na formação de processos essenciais para a defesa do hospedeiro. Nessa etapa da vida, agressões nutricionais poderão ocasionar comprometimento do sistema imunológico, com seqüelas na capacidade de defesa do indivíduo adulto ${ }^{1}$. Dependendo da intensidade e da duração das alterações nutricionais, as conseqüências terão impacto maior ou menor sobre todo o organismo no futuro².

Na desnutrição, a maioria dos mecanismos de defesa do organismo está prejudicada³. Além 
disso, a infecção é a maior causa de morbidade e mortalidade em indivíduos severamente desnutridos $^{4}$

A desnutrição energético-protéica está associada ao enfraquecimento da imunidade mediada por células, da função fagocítica, do sistema de complemento, da concentração de anticorpos e da produção de citocinas ${ }^{5}$. Nesta condição várias funções dos macrófagos encontram-se comprometidas ${ }^{6}$. Estas células são de importância fundamental no controle, na resolução dos processos infecciosos e na regulação da homeostase por serem iniciadoras da resposta inflamatória, por participarem do processo de reparação tecidual e por estarem envolvidas na resposta imune tanto inata quanto adaptativa.

A administração parenteral de endotoxina proveniente de bactérias Gram negativas, como o lipopolissacarídio (LPS), induz a migração de leucócitos sangüíneos para o sítio inflamatório/ infeccioso. Nesse particular, o pulmão é sensível aos efeitos do LPS, seguido do fígado, do intestino e do rim $^{7}$

No foco de injúria tecidual, fatores quimiotáticos atraem células sanguíneas que, por diapedese, atravessam a barreira endotelial. Dentre estas células, os neutrófilos estão em maior número, seguidos dos monócitos que se transformam em macrófagos nos tecidos.

A ativação dos macrófagos por endotoxinas induz a produção intracelular dos ânions superóxido $\left(\mathrm{O}_{2}-\right)$, do peróxido de hidrogênio $\left(\mathrm{H}_{2} \mathrm{O}_{2}\right)$, e de outros potentes produtos microbicidas que são responsáveis pela destruição dos microrganismos fagocitados ${ }^{8,9}$. O conjunto de substâncias, como a enzima superóxido dismutase (SOD), que neutraliza os efeitos danosos dos radicais livres de oxigênio constitui o sistema de defesa antioxidante ${ }^{10}$.

Em função da alta prevalência de desnutrição nos países em desenvolvimento é importante a realização de trabalhos experimentais, a fim de avaliar suas conseqüências nos diversos sistemas orgânicos. Assim, torna-se de extrema importância o estudo de eventuais relações entre a desnutrição neonatal, seguida de recuperação nutricional, e a resposta inflamatória, durante o curso de uma infecção no organismo adulto. Diante disso, este trabalho teve como objetivo avaliar o efeito da desnutrição neonatal, seguida de recuperação nutricional, sobre o recrutamento celular para o pulmão e a atividade oxidante e antioxidante de macrófagos alveolares após endotoxemia em ratos adultos.

\section{M É T O D O S}

Foram utilizados 48 ratos machos Wistar (90-120 dias), provenientes da colônia do Biotério do Departamento de Nutrição da Universidade Federal de Pernambuco (UFPE). Os animais foram mantidos em temperatura controlada $\left(22^{\circ} \mathrm{C}\right.$ Desvio-padrão $\mathrm{DP}=1^{\circ} \mathrm{C}$ ) com ciclo fotoperiódico de claro-escuro de 12:12h e com livre acesso à água e à ração. Um dia após o nascimento, a ninhada foi padronizada em 6 filhotes machos por mãe. Neste mesmo dia, adotado como primeiro dia de vida do animal, as ninhadas foram divididas em 2 grupos: Nutrido (N) - constituído por 24 filhotes amamentados por mães submetidas à dieta con-tendo $23 \%$ de proteína (Labina-Purina do Brasil); Desnutrido (D) - constituído por 24 filhotes amamentados por mães submetidas à dieta contendo $8 \%$ de proteína (Dieta Básica Regional - DBR) ${ }^{11}$ durante os primeiros 21 dias após o nascimento. Atualmente, a DBR vem sendo usada como modelo experimental para estudo da desnutrição, por induzir, no rato, quadro carencial semelhante ao do marasmo verificado em populações humanas ${ }^{12}$. Durante o período neonatal, foram registrados diariamente os pesos corporais em balança eletrônica digital (Marte, modelo S-4000), a fim de monitorar o peso durante a manipulação nutricional. A partir do $22^{\circ}$ dia de vida até o final do experimento, a pesagem foi realizada em dias alternados, objetivando acompanhar a recuperação nutricional dos animais. Após o desmame $\left(22^{\circ} \mathrm{dia}\right)$, os animais foram separados de suas mães e passaram a receber dieta contendo $23 \%$ de proteína (Labina-Purina do Brasil) até o final do experimento. 


\section{Administração de LPS}

No período dos experimentos (90-120 dias), o grupo Nutrido ( $\mathrm{N}$ ) foi dividido em dois grupos: Nutrido (N) e Nutrido Endotoxêmico (NLPS). Da mesma forma, o grupo Desnutrido (D) foi dividido em dois grupos: Desnutrido (D) e Desnutrido Endotoxêmico (DLPS). Para obtenção dos grupos endotoxêmicos (NLPS e DLPS), os animais receberam injeção intraperitonial (i.p.) de LPS (sorotipo de Escherichia coli; 055:B5, Sigma) na dose de $1 \mathrm{mg} / \mathrm{kg}$ de peso corporal, preparado com $\mathrm{NaCl}$ a $0,9 \%$. Os grupos $\mathrm{N}$ e $\mathrm{D}$ receberam, pela mesma via, $\mathrm{NaCl}$ a $0,9 \%$ em igual proporção. Vinte e quatro horas após a administração do LPS $^{13}$ coletou-se sangue e lavado broncoalveolar (LBA) de cada animal para estudo.

\section{Análise das células do sangue periférico}

Coletou-se alíquota de sangue $(0,5 \mathrm{~mL}) \mathrm{da}$ cauda dos animais para a contagem das células. Utilizou-se a solução de TURK para a contagem total. Os leucócitos foram contados em Câmara de Neubauer com auxílio do microscópio óptico em lente cujo aumento foi de 40X. Para a contagem diferencial utilizou-se a técnica do estiraço sangüíneo, e as lâminas foram coradas com o kit Panótico Rápido, LB-Laborclin Ltda. Após preparação, foram examinadas ao microscópio óptico com objetiva de 100x sob imersão. Os elementos figurados foram contabilizados pelo contador eletrônico da marca Kacil com teclas correspondentes a cada tipo de célula. A partir dos dados obtidos foram calculados os valores absolutos e relativos para cada tipo de célula.

\section{Lavado broncoalveolar}

O lavado broncoalveolar foi obtido de acordo com a técnica utilizada por De Castro et al. ${ }^{13}$. Os animais foram anestesiados com uretana $12,5 \%$ na proporção de $8 \mathrm{~mL} / \mathrm{kg}$ i.p. $\mathrm{O}$ lavado broncoalveolar (LBA) foi coletado após a introdução de salina a 0,9\% através de uma cânula plástica inserida na traquéia e, em seguida, várias alíquotas de $3 \mathrm{~mL}$ do lavado foram aspiradas, coletadas e adicionadas em tubos cônicos de polipropileno de 50mL (Falcon, Sigma). Recuperouse, aproximadamente, $30 \mathrm{~mL}$ de LBA de cada animal.

\section{Análise das células do lavado broncoalveolar}

A contagem total das células foi realizada a partir de uma amostra do LBA, diluído de 1:10, em corante azul de trypan. A contagem diferencial foi realizada a partir de lâminas citocentrifugadas a 800rpm/10min (Cytopro ${ }^{\mathrm{TM}}$ - Cytocentrifuge Wescor), coradas com o kit Panótico Rápido e lidas ao microscópio óptico com objetiva de 100x sob imersão. A partir dos dados obtidos foram calculados os valores absolutos e relativos para cada tipo de célula.

\section{Cultura de macrófagos alveolares}

Centrifugaram-se amostras do LBA a 1500 rpm durante 15 minutos. O precipitado que corresponde às células foi ressuspendido em RPMI 1640 (Gibco-Invitrogen Corporation) contendo 3\% de soro fetal bovino (Gibco-Invitrogen Corporation) e antibióticos (penicilina 100U/mL e estreptomicina $100 \mu \mathrm{g} / \mathrm{mL}$ ). As células foram transferidas para placas de cultura de 6 poços com $35 \mathrm{~mm}$ de diâmetro cada (Falcon), nas quais foram dispensados $2 \mathrm{~mL}$ da suspensão em uma proporção de $10^{6}$ células/mL de RPMI 1640 em cada poço. Após $1 \mathrm{~h}$ na incubadora a $37^{\circ} \mathrm{C}$ e $5 \% \mathrm{CO}_{2}$, desprezouse o sobrenadante com as células não aderentes e adicionou-se $2 \mathrm{~mL}$ de RPMI, deixando-se as placas por mais $1 \mathrm{~h}$ em incubadora para estabilização das células.

\section{Análise da produção de superóxido}

$\mathrm{O} \mathrm{O}_{2}^{-}$foi induzido pela adição de acetato miristato de forbol/PMA (Sigma) em solução de Hanks (HBSS, Gibco-Invitrogen Corporation), na concentração de $2 \mu \mathrm{g} / \mathrm{mL}$. Foram preparados 2 
sistemas de análise descontínua avaliados na primeira e na segunda hora. A especificidade do ensaio foi garantida pela adição de superóxido dismutase (SOD) de eritrócitos bovinos contendo $3000 \mathrm{U} / \mathrm{mg}$ de proteína em solução final de 3mg/ $\mathrm{mL}$ em água destilada (Sigma) ${ }^{14}$. Para o preparo destes sistemas foram utilizados macrófagos em cultura ( $2 \times 10^{6}$ células por $2 \mathrm{~mL}$ de RPMI 1640), com ou sem a presença de SOD. Os sistemas foram mantidos em incubadora a $37^{\circ} \mathrm{C}$, atmosfera úmida, $5 \%$ de $\mathrm{CO}_{2}$, por $10 \mathrm{~min}$ (ativação da SOD). O ferrocitocromo c tipo IV de mitocôndria de coração de cavalo, $30 \mathrm{mg} / \mathrm{mL}$ em HBSS, $2.4 \times 10^{-3}$ $M$, (Sigma) foi adicionado às células para quantificar a formação de $\mathrm{O}_{2}^{-}$por meio da redução do ferrocitocromo c. Amostras de 700 $\mu$ l foram retiradas de cada sistema. A $1^{\text {a }}$ alíquota recolhida correspondia ao tempo zero de cada sistema e as amostras subseqüentes foram coletadas em intervalos regulares de tempo. Medidas espectrofotométricas foram realizadas a $550 \mathrm{~nm}$ para determinar o grau de redução do ferrocitocromo c dos sobrenadantes. A curva de $\mathrm{O}_{2}^{-}$foi obtida pela conversão dos valores de absorbância para nanomoles de $\mathrm{O}_{2}^{-} /$min usando-se a fórmula: $[O]=205,49 \times$ valor da absorbância $x$ volume da amostra coletada ${ }^{15}$.

\section{Liberação de óxido nítrico}

A produção de óxido nítrico foi determinada a partir de plasma e de macrófagos em cultura segundo o método descrito por Feder \& Laskin ${ }^{16}$. Após $24 \mathrm{~h}$ de estímulo in vitro com lipopolissacarídio $(10 \mu \mathrm{g} / \mathrm{mL})$, os macrófagos estimulados e os não estimulados com LPS foram avaliados quanto à liberação de óxido nítrico (ON). A concen-tração de nitrito/nitrato, medida indireta da síntese de ON, foi calculada pela média de uma curva padrão de $\mathrm{NaNO}_{2}$ e os dados foram expressos em $\mu \mathrm{M} / \mathrm{mL}$ de nitrito/nitrato.

\section{Atividade da enzima superóxido dismutase}

A atividade da enzima superóxido dismutase (SOD) foi determinada pelo preparo de
4 sistemas com avaliação nos tempos de 0, 5, 10 e $15 \mathrm{~min}$. Para o preparo destes sistemas, foram utilizados macrófagos em cultura $\left(2 \times 10^{6}\right.$ células por $2 \mathrm{~mL}$ de RPMI 1640), solução tampão fosfato (50mM pH 7,8), citocromo c (Sigma - 0,3mM $4 \mu \mathrm{cg} / \mathrm{mL}$ em solução tampão), xantina oxidase (XOD) (Sigma - 25U - 56mU/mL em solução tampão) e SOD (Sigma - 3000U/mg de proteína em solução final de $3 \mathrm{mg} / \mathrm{mL}$ em água destilada). Aos 4 sistemas foram adicionados solução tampão fosfato, citocromo c e hipoxantina. Ao $2^{\circ}$ sistema, além desses reagentes, também foi adicionada a XOD. Os sistemas 3 e 4 foram acrescidos de todos os reagentes, porém a SOD em quantidades diferentes (sistema 3 - SOD 1,5mg/mL; sistema 4 - SOD $3 \mathrm{mg} / \mathrm{mL}$ ). Amostras de $700 \mu \mathrm{L}$ foram retiradas de cada sistema nos tempos determinados (à temperatura de $25^{\circ} \mathrm{C}$ ), sendo efetuadas as leituras das absorbâncias em espectrofotômetro a $550 \mathrm{~nm}$. Para os resultados finais as proteínas foram determinadas pelo método de Lowry et al. ${ }^{17}$ e os dados expressos em UI de SOD por mg de proteína.

\section{Análise estatística}

Na comparação entre os grupos, utilizouse o teste $t$ de Student para os dados paramétricos e o teste de Mann-Whitney para os dados não paramétricos. Os resultados foram representados em média e erro-padrão. A significância foi definida para $p<0,05$.

\section{RES U LT A D O S}

\section{Peso corporal na desnutrição e recuperação nutricional}

Nos primeiros dias de vida os pesos corporais (g) dos grupos nutridos ( $N$ ) e desnutridos (D) foram semelhantes até o $3^{\circ}$ dia. A partir do $4^{\circ}$ dia até o $21^{\circ}$ dia pós-natal os valores dos pesos corporais dos animais desnutridos foram menores $(p<0,05)$ em relação aos dos animais nutridos. Entre o $23^{\circ}$ e o $89^{\circ}$ dia de vida ocorreu a recuperação 
nutricional e os valores dos pesos do grupo desnutrido permaneceram menores $(p<0,05)$, quando comparados aos do grupo nutrido (Figura 1).

\section{Contagens total e diferencial de leucócitos sangüíneos}

Os dados da contagem de leucócitos no sangue periférico (Tabela 1) indicam que a desnutrição neonatal não alterou o número de leucócitos totais e de neutrófilos, quando comparados os grupos nutrido (N) e desnutrido (D). No entanto, animais desnutridos mostraram uma redução $(p<0,05)$ nos valores de monócitos e eosinófilos com um aumento $(p<0,05)$ no número de linfócitos, quando comparados aos animais nutridos. Na presença de estímulo com lipopolissacarídio (LPS), houve redução $(p<0,05)$ nos valores de leucócitos totais, de monócitos, de eosinófilos e de neutrófilos no grupo desnutrido endotoxêmico (DLPS) em relação ao grupo nutrido endotoxêmico (NLPS). Não houve diferença entre NLPS e DLPS quanto ao número de linfócitos.

\section{Contagens total e diferencial de leucócitos do LBA}

Os dados da contagem de leucócitos no LBA (Tabela 1) indicam que a dieta deficiente ocasionou redução $(p<0,05)$ nos valores de macrófagos alveolares em animais desnutridos, quando comparados aos nutridos. Nesse caso, não foram observadas diferenças quanto ao número de leucócitos totais, linfócitos, eosinófilos e neutrófilos. Na endotoxemia houve redução $(p<0,05)$ de neutrófilos com aumento $(p<0,05)$ de macrófagos no grupo de animais desnutridos endotoxêmicos (DLPS), quando comparado ao grupo de animais nutridos endotoxêmicos (NLPS). Não houve diferença entre os grupos NLPS e DLPS quanto ao número de leucócitos totais, linfócitos e eosinófilos.

\section{Liberação de superóxido por macrófagos}

A produção de superóxido $\left(\mathrm{O}_{2}^{-}\right)$no sobrenadante de cultura de macrófagos (Tabela 2) mostrou-se reduzida $(p<0,05)$ em animais

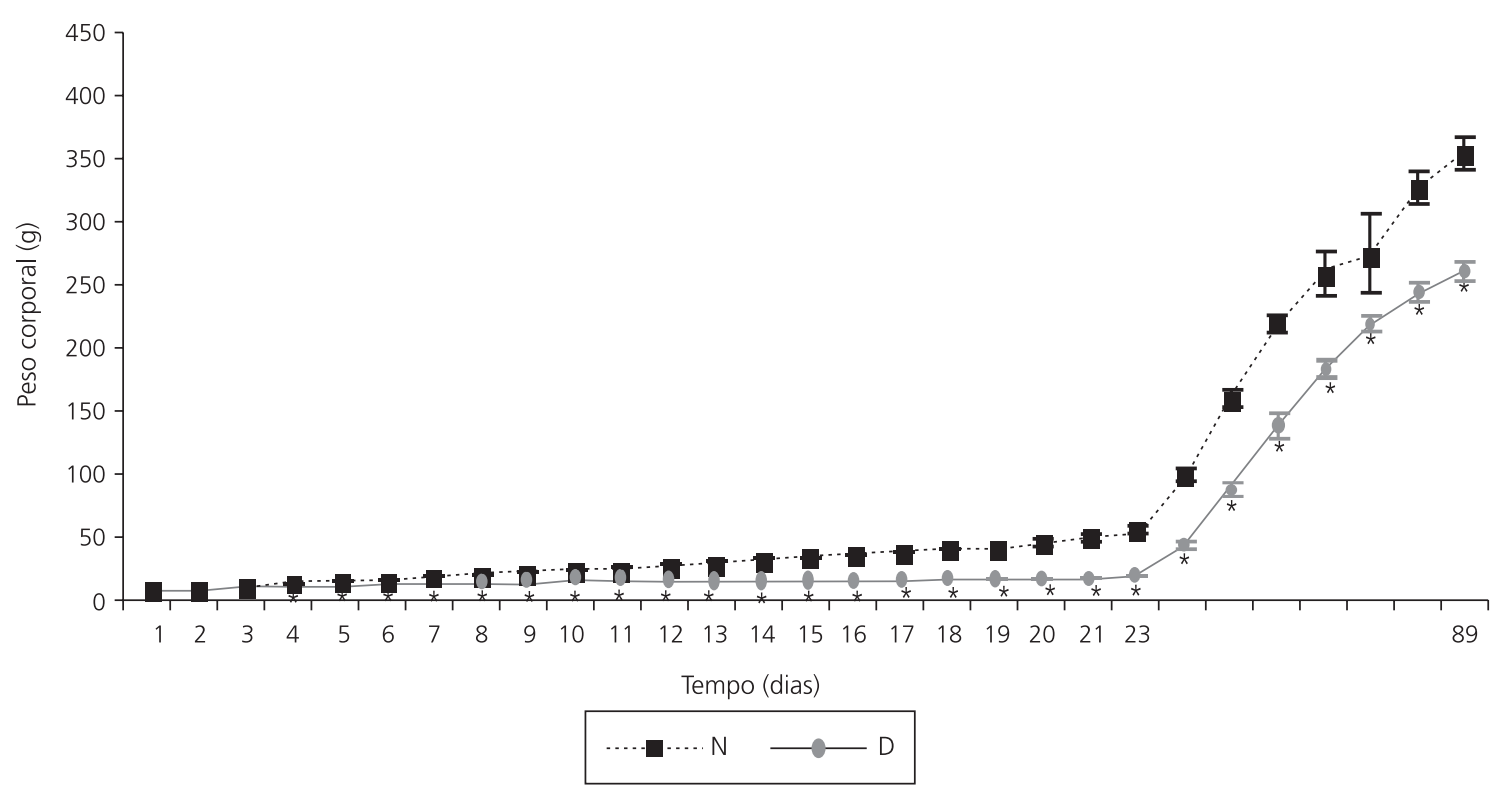

Figura 1. Evolução da curva ponderal durante a desnutrição neonatal (21 dias) e recuperação nutricional (23-89 dias) dos grupos Nutrido (N) e Desnutrido (D).

Nota: Dados expressos em média e erro-padrão para 24 animais, * $p<0,05$. 
desnutridos em relação aos animais nutridos após $2 \mathrm{~h}$ de estímulo dos macrófagos com acetato miristato de forbol (PMA). Na endotoxemia houve redução $(p<0,05)$ na produção de $\mathrm{O}_{2}^{-}$após $1 \mathrm{~h}$ e $2 \mathrm{~h}$ de estímulo com PMA no grupo de animais desnutridos endotoxêmicos (DLPS) em relação ao grupo de animais nutridos endotoxêmicos (NLPS).

\section{Produção de óxido nítrico}

No plasma a produção média de ON (Tabela 2) foi reduzida $(p<0,05)$ no grupo desnutrido em relação ao grupo nutrido. No entanto, não houve diferença entre os grupos de animais nutridos endotoxêmicos (NLPS) e desnutridos

Tabela 1. Contagem de leucócitos em sangue e lavado broncoalveolar (LBA). Os resultados são representados em média (M) e erropadrão (EP) para 12 animais.

\begin{tabular}{|c|c|c|c|c|c|c|c|c|}
\hline \multirow{3}{*}{ Grupos } & \multicolumn{8}{|c|}{ Contagem de células $\times 10^{3} / \mathrm{mL}$ de sangue ou LBA } \\
\hline & \multicolumn{2}{|c|}{$\mathrm{N}$} & \multicolumn{2}{|c|}{$\mathrm{D}$} & \multicolumn{2}{|c|}{ NLPS } & \multicolumn{2}{|c|}{ DLPS } \\
\hline & M & EP & M & EP & M & EP & M & EP \\
\hline \multicolumn{9}{|l|}{ Sangue } \\
\hline Leucócitos totais & 13,99 & 0,66 & 12,44 & 1,07 & 19,77 & 1,58 & 13,49 & $1,01 \#$ \\
\hline \multirow[t]{2}{*}{ Monócitos } & 0,83 & 0,08 & 0,06 & $0,02^{*}$ & 1,05 & 0,18 & 0,43 & $0,14 \#$ \\
\hline & 6,46 & $0,56 \%$ & 0,58 & $0,19 \%$ * & 4,92 & $0,48 \%$ & 2,91 & $0,93 \% \#$ \\
\hline \multirow[t]{2}{*}{ Linfócitos } & 9,67 & 0,59 & 9,81 & 1,08 & 9,30 & 1,45 & 6,84 & 0,63 \\
\hline & 69,46 & $2,17 \%$ & 77,08 & $2,89 \%$ * & 45,07 & $4,89 \%$ & 50,75 & $3,45 \%$ \\
\hline \multirow[t]{2}{*}{ Eosinófilos } & 0,51 & 0,06 & 0,13 & $0,03^{*}$ & 0,49 & 0,09 & 0,19 & $0,05 \#$ \\
\hline & 3,92 & $0,47 \%$ & 1,25 & $0,37 \%$ * & 2,61 & $0,59 \%$ & 1,33 & $0,41 \%$ \\
\hline \multirow[t]{2}{*}{ Neutrófilos } & 2,89 & 0,26 & 2,40 & 0,20 & 8,75 & 1,14 & 6 & $0,57 \#$ \\
\hline & 20,00 & $1,91 \%$ & 21,08 & $2,93 \%$ & 47,38 & $4,93 \%$ & 45 & $3,37 \%$ \\
\hline \multicolumn{9}{|l|}{$\angle B A$} \\
\hline Leucócitos totais & 483,33 & 29,72 & 400 & 24,61 & 683,33 & 82,41 & 575 & 80,83 \\
\hline \multirow[t]{2}{*}{ Macrófagos } & 458,16 & 29,35 & 370,66 & $22,93^{*}$ & 551,25 & 70,30 & 511,08 & 74,37 \\
\hline & 94,64 & $0,82 \%$ & 92,83 & $1,11 \%$ & 80,68 & $2,67 \%$ & 89,66 & $2,48 \% \#$ \\
\hline \multirow[t]{2}{*}{ Linfócitos } & 13,00 & 2,36 & 19,16 & 5,26 & 12,16 & 3,52 & 20 & 6,15 \\
\hline & 2,92 & $0,51 \%$ & 4,58 & $1,10 \%$ & 1,25 & $0,26 \%$ & 3,33 & $0,98 \%$ \\
\hline \multirow[t]{2}{*}{ Eosinófilos } & 2,91 & 1,58 & 0,66 & 0,44 & 5,25 & 2,64 & 3,33 & 1,52 \\
\hline & 0,57 & $0,27 \%$ & 0,16 & $0,11 \%$ & 0,62 & $0,23 \%$ & 0,41 & $0,19 \%$ \\
\hline \multirow[t]{2}{*}{ Neutrófilos } & 9,25 & 2,21 & 9,5 & 2,34 & 114,66 & 18,92 & 40,58 & 18,83\# \\
\hline & 1,85 & $0,41 \%$ & 2,41 & $0,58 \%$ & 17,43 & $2,70 \%$ & 6,58 & $2,43 \% \#$ \\
\hline
\end{tabular}

* $p<0,05$ na comparação entre os grupos nutrido (N) e desnutrido (D); \# $p<0,05$ na comparação entre os grupos nutrido endotoxêmico (NLPS) e desnutrido endotoxêmico (DLPS). Os dados em negrito representam respectivamente a média (M) e o erro-padrão (EP) em valores percentuais.

Tabela 2. Atividade oxidante $\left(\mathrm{O}_{2}^{-}\right.$e $\left.\mathrm{ON}\right)$ em sobrenadante de cultura de macrófagos e de plasma. Os resultados são representados em média (M) e erro-padrão (EP) para 12 animais.

\begin{tabular}{|c|c|c|c|c|c|c|c|c|c|c|}
\hline \multirow[t]{2}{*}{ Grupos } & \multicolumn{2}{|c|}{$\begin{array}{c}\mathrm{O}_{2}^{-} 1 \mathrm{~h} \\
\text { (nmoles/mL) }\end{array}$} & \multicolumn{2}{|c|}{$\begin{array}{c}\mathrm{O}_{2}^{-} 2 \mathrm{~h} \\
(\mathrm{nmoles} / \mathrm{mL})\end{array}$} & \multicolumn{2}{|c|}{$\begin{array}{l}\text { ON plasma } \\
(\mu \mathrm{M} / \mathrm{mL})\end{array}$} & \multicolumn{2}{|c|}{$\begin{array}{c}\text { ON sobrenadante de } \\
\text { cultura de MA sem } \\
\text { estímulo com LPS }(\mu \mathrm{M} / \mathrm{mL})\end{array}$} & \multicolumn{2}{|c|}{$\begin{array}{l}\text { ON sobrenadante de } \\
\text { cultura de MA com } \\
\text { estímulo de LPS na dose } \\
\text { de } 10 \mu \mathrm{g} / \mathrm{mL}(\mu \mathrm{M} / \mathrm{mL})\end{array}$} \\
\hline & $M$ & EP & $M$ & EP & $M$ & EP & $M$ & EP & $M$ & EP \\
\hline$N$ & 13,35 & 0,97 & 23,26 & 2,23 & 24,65 & 3,02 & 49,78 & 7,47 & 92,9 & 5,44 \\
\hline $\mathrm{D}$ & 11,75 & 0,89 & 16,17 & $1,12^{*}$ & 16,6 & 1,74 * & 36,19 & 4,56 & 72,45 & $6,87^{*}$ \\
\hline NLPS & 20,04 & 1,85 & 31,82 & 2,44 & 27,47 & 5,86 & 68,6 & 9,09 & 101,75 & 7,68 \\
\hline DLPS & 13,45 & $0,50 \#$ & 18,10 & $0,56 \#$ & 25,87 & 5,47 & 43,86 & $3,53 \#$ & 84,89 & 3,18 \\
\hline
\end{tabular}

$\mathrm{O}_{2}$; superóxido; ON, óxido nítrico; * $p<0,05$ na comparação entre os grupos nutrido (N) e desnutrido (D); \# $p<0,05$ na comparação entre os grupos nutrido endotoxêmico (NLPS) e desnutrido endotoxêmico (DLPS). 
endotoxêmicos (DLPS). No sobrenadante de cultura de macrófagos não estimulados com LPS in vitro, houve redução $(p<0,05)$ na produção de ON no grupo DLPS em relação ao grupo NLPS. Nesse caso, não houve diferença entre os animais do grupo nutrido (N) e desnutrido (D). No sobrenadante de cultura de macrófagos estimulados com LPS in vitro, houve redução $(p<0,05)$ significante na produção de $\mathrm{ON}$ em animais desnutridos, quando comparados aos animais nutridos. Entretanto, não se observou diferença entre os grupos NLPS e DLPS.

\section{Atividade da superóxido dismutase - SOD}

A atividade da SOD (Figura 2) mostrou-se reduzida $(p<0,05)$ em animais desnutridos em relação aos animais nutridos nos tempos de $10 \mathrm{~min}$ e 15min. Na presença de estímulo com LPS houve redução $(p<0,05)$ na atividade da SOD nos tempos de $0,5 \mathrm{~min}, 10 \mathrm{~min}$ e $15 \mathrm{~min}$ no grupo de animais desnutridos endotoxêmicos em relação ao grupo de animais nutridos endotoxêmicos.

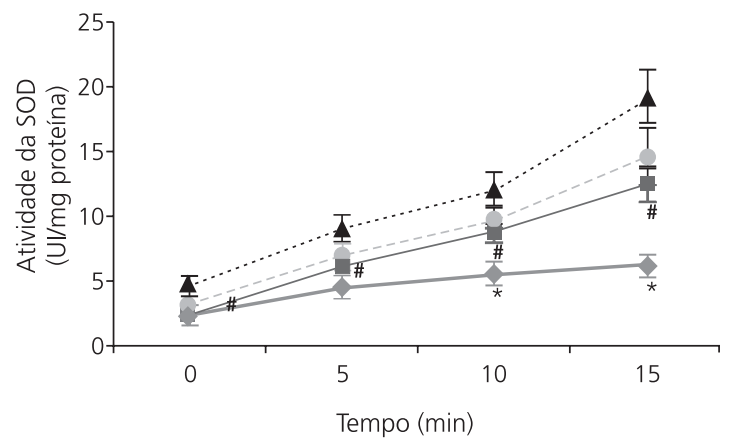

\begin{tabular}{|c|c|c|c|}
\hline$--\mathrm{N}$ & $\multimap D$ & $\cdots \Delta$ NLPS & - DLPS \\
\hline
\end{tabular}

Figura 2. Atividade da superóxido dismutase (SOD) em sobrenadante de cultura de macrófagos nos tempos de 0 , $5 \mathrm{~min}, 10 \mathrm{~min}$ e $15 \mathrm{~min}$. Os resultados são representados em média e erro-padrão para 12 animais.

Nota: * $p<0,05$ na comparação entre os grupos nutrido (N) e desnutrido (D); \# $p<0,05$ na comparação entre os grupos nutrido endotoxêmico (NLPS) e desnutrido endotoxêmico (DLPS).
D I S C U S S Ã O

No presente estudo a desnutrição imposta no período neonatal, seguida de recuperação nutricional, produziu seqüela no animal adulto. Assim, este modelo de desnutrição causou redução do recrutamento de células inflamatórias para o pulmão na presença ou não de estímulo com lipopolissacarídio, comprometeu a atividade oxidante-antioxidante de macrófagos alveolares (MA) antes e após endotoxemia, e acarretou déficit ponderal com início ainda no aleitamento e persistindo até a vida adulta do animal.

Em sua maioria, a dieta básica regional (DBR) é constituída em sua composição por $96 \%$ de proteína de origem vegetal e apenas $4 \%$ de proteína de origem animal ${ }^{11}$, o que a torna ainda mais deficiente em termos protéicos. Os dados do presente estudo mostram que a desnutrição neonatal produziu reduções do peso corporal tanto no período de aleitamento quanto na fase de recuperação nutricional. Aos 4 dias de idade observouse peso menor nos animais desnutridos, quando comparados aos animais nutridos. Tal redução já foi descrita em estudos ${ }^{18,19}$ que empregaram a DBR como modelo experimental de desnutrição. De acordo com Guzmán-Silva et al. ${ }^{20}$, animais desnutridos durante o período pré e pós-natal, ao serem alimentados com dieta adequada nutricionalmente, rapidamente melhoraram seu peso, no entanto, o peso alcançado após o período de recuperação foi inferior ao dos animais controle.

A oferta de dieta normoprotéica a partir do desmame não se mostrou suficiente para igualar os pesos dos animais desnutridos com os dos animais nutridos. Esta interferência no crescimento e desenvolvimento corporais dos filhotes aleitados pode ter sido provocada por um comprometimento na qualidade do leite materno, em razão da desnutrição protéica sofrida pelas ratas durante a lactação.

Além de causar déficit permanente no peso corporal, a desnutrição, no período de expansão das populações de leucócitos e de 
formação de órgãos linfóides ${ }^{21}$, ocasionou uma redução do recrutamento destas células para o pulmão de ratos na idade adulta. Tal fato foi observado pela diminuição de MA em animais desnutridos precocemente. Além disso, a desnutrição reduziu de forma marcante o recrutamento de neutrófilos após administração sistêmica de lipopolissacarídios. As contagens total e diferencial dos leucócitos em sangue periférico e no lavado broncoalveolar (LBA) foram efetivas para demonstrar, de forma indireta, a migração destas células para o sítio inflamatório/infeccioso.

Ainda não existem pesquisas relacionando desnutrição neonatal seguida de recuperação nutricional com o recrutamento celular para o pulmão no animal adulto. Neutrófilos e macrófagos são fagócitos e têm a capacidade de internalizar partículas inertes, células alteradas do indivíduo, microrganismos e parasitas. Os sinais quimiotáticos gerados no local da inflamação são os responsáveis pelo recrutamento das células fagocíticas. Esses fagócitos migram da corrente sangüínea para o local no qual há lesão tecidual22.

Estudos revelam a diminuição no número de macrófagos peritoneais ${ }^{23}$ e macrófagos alveolares $^{24}$ na desnutrição. Outros trabalhos ${ }^{25,26}$ demonstraram que a desnutrição inibiu a migração de neutrófilos para o foco inflamatório de camundongos sem, no entanto, avaliarem a interferência da endotoxemia no modelo experimental de desnutrição. Nesta pesquisa, a diminuição do número de neutrófilos recrutados para o pulmão, evidenciada somente após a endotoxemia, pode sugerir que a desnutrição neonatal causa um maior comprometimento da resposta inflamatória frente às infecções na vida adulta.

A desnutrição reduz a imunidade em geral, sobretudo, provoca alterações no pulmão, comprometendo a função dos macrófagos alveolares. De acordo com Souza et al. ${ }^{27}$, diante de estímulos inflamatórios, os macrófagos de animais desnutridos não respondem com a mesma intensidade ou da mesma maneira que os macrófagos oriun- dos dos animais nutridos, possibilitando, ou permitindo, o desenvolvimento dos processos inflamatórios e/ou infecciosos.

A avaliação da síntese de substâncias oxidantes é uma forma sensível e conveniente de monitorar a função dos macrófagos ${ }^{14}$. Neste estudo, demonstrou-se que a desnutrição neonatal reduziu a liberação de $\mathrm{O}_{2}$; um potente microbicida natural ${ }^{14}$, por MA na vida adulta. Redmond et al. ${ }^{28}$ relataram prejuízos na produção de $\mathrm{O}_{2}^{-}$em macrófagos peritoneais de animais com desnutrição ocorrida por curto ou longo período. Estudo realizado no laboratório com macrófagos alveolares deste grupo de pesquisadores ${ }^{18}$ comprovou redução na produção de $\mathrm{O}_{2}^{-}$utilizando-se o mesmo modelo de desnutrição empregado no presente estudo. Vale ressaltar que, nesta pesquisa, a produção de $\mathrm{O}_{2}{ }^{-}$mostrou-se reduzida desde a $1^{\mathrm{a}} \mathrm{h}$ de estímulo com acetato miristato de forbol nos animais desnutridos endotoxêmicos. Já no grupo de animais desnutridos não endotoxêmicos, tal fato foi observado apenas $2 \mathrm{~h}$ após estímulo de macrófagos com acetato miristato de forbol. Esses resultados sugerem maior prejuízo na função microbicida de macrófagos de animais desnutridos após endotoxemia permitindo evidenciar, após estímulo com lipopolissacaridio, um maior comprometimento na produção $\mathrm{de}_{2}^{-}$. Assim como observado para a síntese de $\mathrm{O}_{2}^{-}$, a desnutrição neonatal também acarretou prejuízo na liberação de óxido nítrico em sobrenadante de cultura de macrófagos além do plasma.

Neste estudo, quando a produção de ON em macrófagos foi induzida pelo estímulo por $24 \mathrm{~h}$ com o LPS, in vitro, houve redução desta síntese nos animais desnutridos. No plasma também se observou redução dos níveis de ON no grupo desnutrido. Alguns estudos mostram déficit na produção de ON na desnutrição ${ }^{29,30}$. Dong et al. ${ }^{31}$ verificaram a diminuição na liberação desse agente microbicida por MA de ratos desnutridos. Contudo, esses trabalhos não se referem a situações de endotoxemia e desnutrição neonatal. 
Nesta pesquisa foi evidenciada redução na liberação de ON por macrófagos não tratados com LPS, in vitro, após endotoxemia. A desnutrição veio a acentuar esse efeito.

A atividade da enzima antioxidante superóxido dismutase, neste estudo, mostrou-se reduzida em MA de ratos adultos submetidos à desnutrição neonatal. Isto foi observado na presença ou não de endotoxemia. De acordo com Leite \& Sarni ${ }^{32}$, o desequilíbrio entre a produção de radicais livres, como superóxido e óxido nítrico, e suas respectivas neutralizações poderia ser explicado pela diminuição das defesas antioxidantes que ocorre durante a desnutrição. Estudos demonstram atividade reduzida da SOD em soro de crianças desnutridas ${ }^{33,34}$. Outro estudo ${ }^{35}$ demonstrou que ocorre redução na atividade da SOD em tecido pulmonar na deficiência nutricional, porém não há relatos na literatura quanto à produção desta enzima por MA neste modelo de desnutrição. Apesar da importância da SOD em impedir o acúmulo de radicais livres de oxigênio, como $\mathrm{O}_{2}^{-}$, é bem provável que a atividade reduzida desta enzima tenha sido evidenciada em virtude de uma marcante redução na produção do agente oxidante $\mathrm{O}_{2}^{-}$. Outro fato que deve ser salientado é que na endotoxemia, esta redução foi observada em todos os tempos de avaliação (0-15min), enquanto que na ausência de estímulo com LPS tal situação foi evidenciada apenas a partir dos 10min. Em adição, esses dados podem indicar que a desnutrição neonatal causa comprometimento no sistema de defesa antioxidante, e que essa situação acrescida de um estímulo como a endotoxemia provoca maior comprometimento da resposta do animal na vida adulta.

Apesar de existirem muitos estudos sobre o efeito da desnutrição sobre o sistema imune, ainda há muito a ser investigado acerca do seu efeito tardio pós recuperação nutricional. Dessa forma, os dados encontrados nesta pesquisa devem servir de subsídio para outros trabalhos com o objetivo de investigar o significado funcional das alterações nesse sistema de defesa oxidante- antioxidante em animais desnutridos endotoxêmicos.

Este estudo permite sugerir que a desnutrição neonatal, mesmo seguida de recuperação nutricional, compromete a resposta inflamatória pulmonar de ratos adultos diminuindo o recrutamento de células inflamatórias para o pulmão e a atividade oxidante-antioxidante dos macrófagos alveolares. A endotoxemia contribui para evidenciar essas seqüelas da resposta do hospedeiro frente a este modelo de desnutrição.

\section{COLABORADORES}

J.F. MELO participou da elaboração do projeto de pesquisa, da estratégia experimental, da coleta de dados, da tabulação, da discussão dos resultados e da redação do artigo. E.M.C. MACEDO participou da preparação dos grupos experimentais, da manutenção dos animais no biotério e da coleta das amostras. R.P.P. SILVA participou da preparação dos grupos experimentais, da manutenção dos animais no biotério e da coleta das amostras. M.T. VIANA participou da tabulação dos dados e do estudo estatístico. W.T.F. SILVA participou da coleta de dados e da discussão dos resultados. C.M.M.B. CASTRO participou da elaboração do projeto de pesquisa, da tabulação, da discussão dos resultados e da elaboração do artigo.

\section{REFERÊ NCIAS}

1. Cunningham-Rundles S, Mcneeley DF, Moon A. Mechanisms of nutrient modulation of the immune response. J Allergy Clin Immunol. 2005; 115(6): 1119-28.

2. Guedes RCA, Melo APR, Teodosio NR. Nutrição adequada: a base do funcionamento cerebral. Cienc Cult. 2004; 56(1):32-5.

3. Chandra RK. Nutrition and the immune system: an introduction. Am J Clin Nutr. 1997; 66(2): 460-3.

4. Morgan $\mathrm{G}$. What, if any, is the effect of malnutrition on immunological competence? Lancet. 1997; 349(9066):1693-5.

5. Chandra RK. Nutrition and the immune system from birth to old age. Eur J Clin Nutr. 2002; 56(3):S73-6. 
6. Borelli P, Souza IP, Borojevic R, Dagli MLZ, Kang $H C$. Protein Malnutrition: Some Aspects of the in vitro adhesion of peritoneal mouse macrophages. Ann Nutr Metab. 1998; 42(6): 367-73.

7. Welbourn CRB, Young Y. Endotoxin, septic shock and acute lung injury: neutrophils, macrophages and inflammatory mediators. Br J Surg. 1992; 79(10):998-1003.

8. Meyer J, Hinder F, Stothert J Jr, Traber LD, Herndon DN, Flynn JT, et al. Increased organ blood flow in chronic endotoxemia is reversed by nitric oxide synthase inhibition. J Appl Physiol. 1994; 76(6): 2785-93.

9. Amersfoort ESV, Berkel TJCV, Kuiper J. Receptors, mediators, and mechanisms involved in bacterial sepsis and septic shock. Clin Microbiol Rev. 2003; 16(3):379-414.

10. Andrade Júnior DR, Souza RB, Santos SA, Andrade DR. Os radicais livres de oxigênio e as doenças pulmonares. J Bras Pneumol. 2005; 31(1):60-8.

11. Teodósio NR, Lago ES, Romani SAM, Guedes RCA. Regional basic diet from Northeast Brazil as a dietary model of experimental malnutrition. Arch Latinoam Nutr. 1990; 40(4):533-47.

12. Ferreira HS, Assunção ML, França AOS, Cardoso EPC, Moura FA. Efetividade da "multimistura" como suplemento de dietas deficientes em vitaminas e/ou minerais na recuperação ponderal de ratos submetidos à desnutrição pós-natal. Rev Nutr. 2005; 18(1):63-74.

13. De Castro CM, Bureau MF, Nahori MA, Dumarey $\mathrm{CH}$, Vargaftig BB, Bachelet $\mathrm{M}$. Modulation by dexamethasone of phospholipase A2 activities in endotoxemic guinea pigs. J Appl Physiol. 1995; 79(4):1271-7.

14. De Castro CMMB, De Castro RM, Medeiros AF, Santos AQ, Silva WTF, Lima Filho JL. Effect of stress on the production of $\mathrm{O} 2$ - in alveolar macrophages. J Neuroimmunol. 2000; 108(1/2):68-72.

15. Johnston Jr RB. Measurement of O2- secreted by monocytes and macrophages. Methods Enzymol. 1984; 105:365-9.

16. Feder LS, Laskin DL. Regulation of hepatic endothelial cell and macrophage proliferation and nitric oxide prodution by GM-CSF, M-CSF and IL-1 b following acute endotoxemia. J Leukoc Biol. 1994; 55(4):507-13.

17. Lowry $\mathrm{OH}$, Rosebrough NJ, Farr AL, Randall RJ. Protein measurement with the folin phenol reagent. J Biol Chem. 1951; 193(1):265-75.
18. Queiros-Santos A. Desnutrição precoce e estresse agudo: aspectos da resposta imunitária em ratos adultos [dissertação]. Recife: Universidade Federal de Pernambuco; 2000.

19. Prazeres FG, Pessoa DCNP, Bion FM, Arnauld TMS. Exercício físico, crescimento e desenvolvimento: estudo em ratos jovens desnutridos pela dieta básica regional (DBR) e recuperados nutricionalmente. Rev Bras Educ Fís Esporte. 2004; 18(1):7-16.

20. Guzmán-Silva MA, Wanderley AR, Macêdo VM, Boaventura GT. Recuperação da desnutrição em ratos mediante rações adicionadas ou não de suplemento alimentar e de vitaminas e minerais durante o período de crescimento. Rev Nutr. 2004; 17(1):59-69.

21. Klasing KC. Nutritional modulation of resistance to infections diseases. Poult Sci. 1998; 77(8): 1119-25.

22. Ben Baruch A, Michiel DF, Oppenheim JJ. Signals and receptors involved in recruitment of inflamatory cells. J Biol Chem. 1995; 270(20): 11703-6.

23. Revillard JP, Cozon G. Experimental models and mechanisms of immune deficiencies of nutritional origin. Food Addit Contam. 1990; 7(1):S82-6.

24. Boles JM, Renault A, Menez JF, Garo B, Youinou P. Dénutrition et immunité respiratoire. Nutr Clin Metab. 1994; 8(1):39-44.

25. Borelli P, Mariano M, Borojevic R. Protein malnutrition: effect on myeloid cell production and mobilization into inflammatory reactions in mice. Nutr Res. 1995; 15(10):1477-85.

26. Ikeda S, Saito H, Inoue T, Fukatsu K, Han I, Furukawa $\mathrm{S}$, et al. Malnutrition impairs CD11b/CD18 expression on circulating polymorphonuclear neutrophils and subsequent exudation into inflammatory sites in the early phase of glycogeninduced murine peritonitis. JPEN J Parenter Enteral Nutr. 2000; 24(5):276-9.

27. Souza IP, Kang HC, Nardinele L, Borelli P. Desnutrição protéica: efeito sobre o espraiamento, fagocitose e atividade fungicida de macrófagos peritoneais. Rev Bras Cienc Farm. 2001; 37(2): 143-51.

28. Redmond HP, Leon P, Lieberman MD, Hofmann K, Shou J, Reynolds JV, et al. Impaired macrophage function in severe protein-energy malnutrition. Arch Surg. 1991; 126(2):192-6.

29. Chan J, Tian Y, Tanaka KE, Tsang MS, Yu K, Salgame $P$, et al. Effects of protein calorie malnutrition on tuberculosis in mice. Proc Natl Acad Sci USA. 1996; 93(25):14857-61. 
30. Anstead GM, Chandrasekar B, Zhao W, Yang J, Perez LE, Melby PC. Malnutrition alters the innate immune response and increases early visceralization following Leishmania donovani infection. Infect Immun. 2001; 69(8):4709-18.

31. Dong W, Selgrade MJK, Gilmour MI, Lange RW, Park P, Luster Ml, et al. Altered alveolar macrophage function in calorie-restricted rats. Am J Respir Cell Mol Biol. 1998; 19(3):462-9.

32. Leite HP, Sarni RS. Radicais livres, anti-oxidantes e nutrição. Rev Bras Nutr Clin. 2003; 18(2): 87-94.

33. Shaaban SY, Nassar MF, Ibrahim SA, Mahmoud SE. Impact of nutritional rehabilitation on enzymatic antioxidant levels in protein energy malnutrition. East Mediterr Health J. 2002; 8(2-3):290-7.

34. Gupta P, Narang M, Banerjee BD, Basu S. Oxidative stress in term small for gestational age neonates born to undernourished mothers: a case control study. BMC Pediatr. 2004; 4:14.

35. Jimoh FO, Odutuga AA, Oladiji AT. Status of lipid peroxidation and antioxidant enzymes in the tissues of rats fed low-protein diet. Pak J Nutr. 2005; 4(6):431-4.

Recebido em: 15/6/2007

Versão final reapresentada em: 27/2/2008

Aprovado em: 25/6/2008 